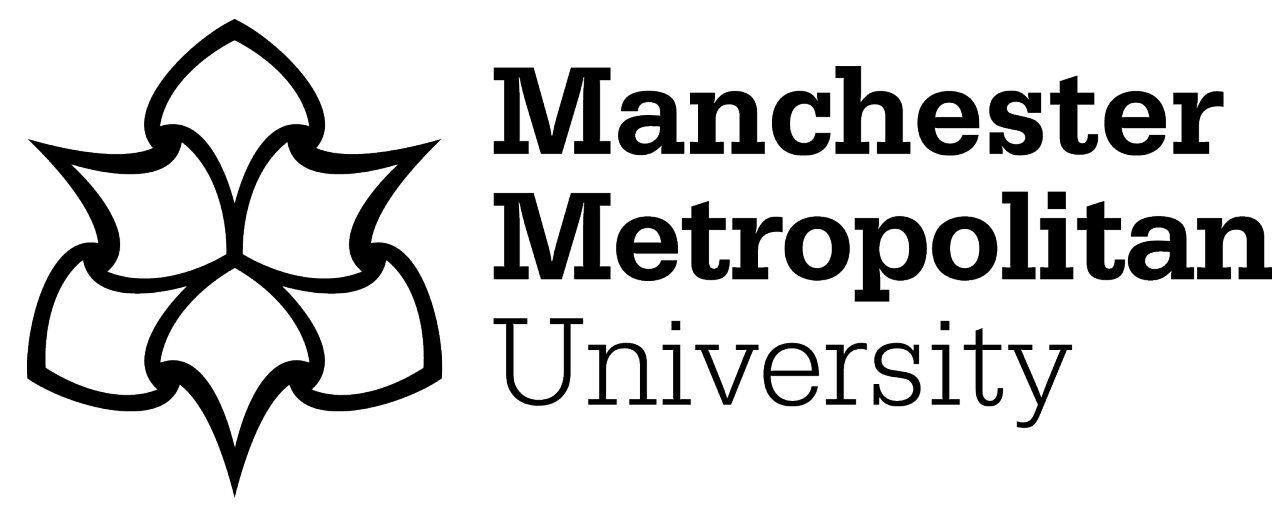

McNicol, Sarah ORCID logoORCID: https://orcid.org/0000-0001-8196-6680 and Leamy, Cathy (2020) Co-creating a graphic illness narrative with people with dementia. Journal of Applied Arts \& Health, 11 (3). pp. 267-280. ISSN 2040-2457

Downloaded from: https://e-space.mmu.ac.uk/626567/

Version: Accepted Version

Publisher: Intellect

DOI: https://doi.org/10.1386/jaah_00040_1

Please cite the published version 


\title{
Co-creating a graphic illness narrative with people with dementia
}

\author{
Sarah McNicol, Manchester Metropolitan University \\ Cathy Leamy, independent cartoonist
}

\begin{abstract}
This article reports on a project which aimed to pilot a collaborative, patient-led approach to comics creation by developing an artistic process that allows people living with dementia to communicate their experiences and express their opinions. People living with dementia are rarely given the opportunity of speaking for themselves in the media; someone else usually speaks on their behalf, for example family or carers. In the novel approach to comics creation reported here, people with early- to mid-stage dementia worked collaboratively with artists to tell their stories as a way to offer alternative perspectives, and help overcome the stigma associated with dementia.
\end{abstract}

\section{Keywords}

Dementia; comics; co-production; stigma; graphic medicine; Alzheimer's disease

\section{Introduction}

Dementia is an umbrella term that includes a number of conditions, for example, Alzheimer's disease, vascular dementia and Lewy body dementia. Worldwide, there are an estimated 46.8 million people living with dementia and the numbers affected are expected to double every 20 years, rising to 115.4 million by 2050 . Another 7.7 million people will develop dementia around the world every year (Alzheimer's Society 2019). In the UK, where the project reported below took place, an estimated 850,000 people are living with dementia, including over 42,000 below the age of 65 (Alzheimer's Society 2019). Worryingly, only 58 per cent of people with dementia in the UK say they are living well (Alzheimer's Society 2014).

As dementia practice and research have progressed, the need to actively involve people with dementia has increasingly been recognised (e.g. Fetherstonhough et al 2013; McKeown et al. 2010). However, it is still the case that people living with dementia are rarely given the opportunity in the media of speaking for themselves; more usually, someone else 
speaks on their behalf, for example family members or carers (Clarke 2006; Kirkman 2006). As a result, the media often emphasise the heavy weight that the illness exerts on the family (Werner et al 2010). In research circles too, attention has tended to be focused on the views and needs of carers or other proxies, while the experiences of people living with dementia have been largely overlooked (e.g. Tanner 2013; Hellström et al. 2007).

The article starts by considering public attitudes and the potential for stigma with regard to dementia, and cultural representations of dementia and graphic illness narratives in particular, before describing the process of working with artists and people with early- to mid-stage dementia to co-create a comic that challenges some of these common representations and assumptions.

\section{Public attitudes towards dementia}

Despite the rising profile of dementia, the stigma associated with the condition remains an apparently intractable problem (Bamford et al. 2014). Focusing on Alzheimer's disease, Behuniak (2011: 70) describes the stigma associated with dementia as, 'dehumanisation based on disgust and terror', which 'infuses the social discourse about AD [Alzheimer's Disease] with a politics of revulsion and fear that separates and marginalises those with AD'. Stigma, the concept from Goffman's discussion of the social treatment of illness, disability and otherness, is a process that devalues. Goffman (1963: 3) explains how, through stigma, the individual is 'reduced in our minds from a whole and usual person to a tainted, discounted one'.

Although some, such as Leibing (2015), argue that there has been a change in attitudes towards dementia, public fear of the condition is still widely reported. For example, recent surveys suggest that people over the age of 55 fear being diagnosed with dementia more than any other condition (Alzheimer's Society 2016). In Alzheimer's Disease International's 2012 survey on overcoming stigma (ADI 2015), 75\% of respondents thought that there was a stigma around people with Alzheimer's disease. This can take many different forms, including enacted stigma, such as a lack of priority given to the individual's quality of life, or felt stigma, for example, self-regulated exclusion from social activities or avoidance of diagnosis (Bamford et al. 2014). Nearly one in four people with dementia (24\%) hide or conceal their diagnosis citing stigma as the main reason and $40 \%$ of people with dementia report not being included in everyday life (ADI 2015). People with dementia often lose their social networks and run the risk of isolation and solitude or 'social death' (Sweeting and Gilhooly 1997). They may also have difficulty in accessing support services; suffer from a 
poor self-image; and experience discrimination (Naue and Kroll 2009). It is therefore unsurprising that the general public perception of dementia is frequently of an aggressive and merciless illness (e.g. Blay and Peluso 2010; Werner 2005), with dementia often being portrayed as the loss of someone before they actually die (Aquilina and Hughes 2006).

\section{Cultural representations of dementia}

In recent years, there has been increasing interest in cultural representations of dementia, contributing to greater public awareness of the condition. A 'proliferation of dementia stories' (Hillman and Latimer 2017: 2) or 'dementia boom' (Swinnen and Schweda 2015: 10) has been witnessed across the mainstream press, television, film, literature and other forms of art and media. However, it is still largely the case that, 'cultural representations of people with dementia....are essentially negative' (Bond et al 2004: 220-1). Furthermore, more attention is usually paid to the experiences of carers than to the experiences of those living with the condition (Beard 2004). There is some evidence that more nuanced stories are starting to be told, however. For example, Hillman and Latimer (2017) highlight Iris (2001), Robot and Frank (2013) and Still Alice (2015) as examples of films that deal with complexity, transformations and humanity, not simply the stereotypes of loss and obliteration so often associated with the portrayal of dementia.

Another important development is the increasing awareness of the value of creative arts practice in dementia (Social Care Institute for Excellence 2013). Active engagement in the arts has been found to have the power to transform the lives of people with dementia through greater fulfilment, confidence, skills development, desire to socialise and the relief of stress (Arts4Dementia). The creative, imaginative and emotional parts of a person with dementia often remain relatively strong, despite the condition's negative effects on their cognitive abilities.

\section{Graphic illness narratives}

Whilst a wide range of arts and cultural activities have potential to have a positive impact on both the lives of people with dementia and public perceptions of the condition, this article focuses on graphic illness narratives, that is, stories told using a comics format. The representation of medical practices or conditions in comics is not new, but since the turn of the millennium there has been growing interest in graphic illness narratives, often known as graphic medicine or graphic pathologies. Graphic narratives are a potentially powerful medium to allow the voices of people with dementia to be heard because, as Danziger- 
Russell (2013: 92) argues, comics 'create the perfect space for the expression of voices that have been previously marginalized'. Through combining text and visual methods of communication, comics offer a means for the expression of interior, or silent, voices, especially of those whose voices are often ignored. Indeed, there is an ever-growing list of graphic illness narratives dealing with a variety of both physical and mental health conditions ${ }^{1}$.These works are often autobiographical and deal directly with the patient experience of illness, or of caring for others with an illness. Research has shown that reading these types of narratives can offer patients and family members opportunities for selfawareness, reassurance, empathy, companionship and ways to explore the impact of illness on family relationships (McNicol 2017). For medical professionals, they can offer new insights into the patient's experience of illness, especially regarding concerns patients might not mention in a clinical setting (Green and Myers 2010).

Unlike graphic narratives about most of other conditions, however, graphic narratives dealing with dementia typically depict the perspective of carers and family members rather than that of the person with dementia. Narratives such as Take Care, Son: The Story of My Dad and His Dementia (Husband 2014); Alzheimer's My Mother and Me (Leavitt 2010); and Dad's Not All There Anymore (Demetris 2015) focus on the impact of dementia on the family. This is, undoubtedly, a highly important consideration; caregivers are often described as 'invisible second patients' (Brodaty and Donkin 2009) and, of course, dementia takes its toll on family members. However, this means that, as in other types of media, people with dementia themselves lack a voice.

\section{Creating comics with people with dementia}

'Comics creation with people with dementia', funded by Arts Council England, aimed to pilot a collaborative, patient-led approach to health comics creation. The project employed a form of community-based participatory research (CBPR), 'a collaborative approach to research that equitably involves all partners in the research process and recognizes the unique strengths that each bring' (Faridi et al 2007). Using this approach, a diverse group of people living with dementia, supported by dementia advocates, worked alongside artists and researchers in a series of arts workshops to find ways to represent and depict their experiences of the condition in a comics format. This method of collaborative production included ongoing consultation with a group of people with early- to mid-stage dementia throughout the creative process, as described below. This is a novel way of working as, while people with a health condition may act in an advisory capacity in the creation of comics, they 
are rarely involved in working collaboratively with an artist to this degree. In this project, people with dementia engaged directly in the design of the comic ensuring their perspectives remained at the centre of the creative outputs. The focus of the workshops was on understanding how they wished themselves and their condition to be represented and exploring how this could best be depicted as comics art.

Workshop participants were recruited via Beth Johnson Foundation (BJF), a national charity dedicated to making the UK age-friendly. The Dementia Advocacy team runs a regular Peer Advocacy Support Group for people living with dementia in and around North Staffordshire who meet regularly to support each other and raise awareness of dementia.

Ethical approval for the project was obtained from Manchester Metropolitan University Faculty of Education Research Ethics Committee. At the start of the project, participants were provided with both written and verbal information about the project, including an opportunity to ask questions, and then asked to sign an informed consent form. Crucially, given the nature of the group and the fact that sessions took place over an extended time period, we repeated the main ethical considerations at the beginning of each session, for example, ensuring participants were happy for the session to be recorded and reminding them they could leave at any point.

\section{Preparatory research}

In the first stage of the project, three members of the peer advocacy support group agreed to take part in an informal discussion about some existing graphic narratives depicting people with dementia. Participants did not read these fully (they felt that some of the texts would not be easy for someone with dementia to read in any event), but rather gave their initial responses and impressions.

One of the first issues discussed was that participants' only previous experience of reading graphic narratives had been children's comics. They were not used to seeing or reading adult comics or graphic novels, so the idea that this format can be used to portray something as serious as dementia could be perplexing: I think if you use the word comic, people will get the wrong impression...people who don't know much about it [dementia] will think, 'Well, it can't be serious then'. This is not an unusual response to graphic illness narratives, as Ashwell and Thomas (2018) have pointed out. Despite their initial reservations, however, when the participants began to look at some of the graphic narratives presented, they expressed more positive opinions about the format. However, they felt that if these were intended to be read by someone with dementia, and not just their carers, the narratives needed 
to be shorter, with a limited amount of text on each page, and in a layout that was easier to follow.

Furthermore, participants felt that the themes and content of many of the examples shared were 'quite negative' and did not correspond to their own experiences of living with dementia. They were keen to stress that, in contrast to the narratives that predominantly portrayed people in the more advanced stages of dementia, 'People live very, very well for quite a long time with dementia'. They felt that focusing on the negative aspects of living with dementia and would not offer much needed hope to people who had been recently diagnosed. Discussing the reasons why existing graphic narratives did not match their own experiences, the group felt it was the fact that they were mostly written from the perspective of a carer or family member, rather than someone with dementia themselves. Participants could understand why someone who had lived through the experience of caring for someone in the advanced stages of dementia might view the condition in this way, but they were keen to stress that this was far from the only way of viewing dementia, and to explore how these alternative ways of viewing dementia might be represented in a comic.

\section{Practical arrangements for comics creation}

In order to create a comic about the experiences of having dementia, we held a series of five workshops over the course of one year. Each session lasted approximately two hours, including short rest/snack breaks. Although not all group members were able to attend on every occasion, there were between five and eight participants at each workshop. Sarah McNicol (the researcher) facilitated the workshops, supported by Cathy Leamy (the main artist) and Jessica Lucas (the supporting artist). As Cathy is based in the United States, she attended the first session in person to meet the group, but took part in the other sessions via Skype (projected on a large television screen in the meeting room). Jessica was therefore involved to work directly with group members, providing support with arts skills as required, The group sat around a single table in the room where the support group regularly meets. Two dementia advocates Betty Machin and Jane Snape from Beth Johnson Foundation were also present at all the workshops. As well as helping to facilitate the sessions, they had a role in providing additional support should group members require it. For example, should thinking about their condition result in people feeling upset or emotional, the dementia advocates would be there to provide support. They would also be to refer members of the group to other services that could help in relation to particular issues raised during the discussion. 
All the workshops were video-recorded. These were not transcribed, but members of the team watched them back afterwards and made notes of the main points, including anything they missed through being engaged in the session. At the start of the project, we provided participants with written and verbal information about the project and asked them to sign a consent form. As the project took place over a number of months, we reviewed this with the group at key points to ensure they were still happy to participate. In the final comic, all group members and dementia advocates are named as collaborators.

It is worth noting that this group is a pre-established one, and is focused on advocacy and awareness-raising rather than arts per se. The workshops therefore included a variety of arts-based activities, but also facilitated discussion and review activities. If we had run the project with an arts-focused group, it may well have been appropriate to use participants' own drawings directly within the comic, but for this group, the approach of using arts activities to generate ideas for a comic that was then drawn by a professional artist was likely to be more successful. Key activities included discussing the impact of living with dementia on participants' daily lives; deciding on the key messages for the comic; providing feedback on character design and constructing biographies; and plotting potential storylines, as well as commenting on a series of progressively more developed drafts of the comic (McNicol, 2019). All draft materials for review were printed out for each participant, rather than shared digitally or a single copy printed and pinned to a wall. Although participants were encouraged to draw, this was optional. Drawing activities included asking participants to represent dementia as a visual metaphor (see below), and drawing panels (using stick figures) to show how a story could be resolved in different ways. We used materials participants were likely to be familiar with (e.g. coloured pencils). In addition to using stick figures, some of the methods we used to help participants feel more at ease drawing were paired activities and the presence of the supporting artist who offered support. Furthermore, the fact that the group was a pre-existing group meant that people already knew each other and many were friends. Our experience and the comic itself might have been very different if we had gathered a group of strangers solely for the purpose of making the comic.

\section{The process of co-creating a comic about dementia}

The following section outlines key aspects of the co-creation of the comic, namely, deciding on key messages; developing characters; and making decisions about the format, design and layout. 


\section{Deciding on key messages for the comic}

It is important to stress that this project did not start with a draft comic, or even pre-defined ideas of what the storyline might be. We were keen that the key themes and messages were identified by the group of people with dementia we were working with (rather than artists, researchers or even dementia advocates). We therefore adopted a variety of approaches to identify messages to convey in the comic, including group discussions about dementia stereotypes versus reality, and asking pairs of participants to complete speech bubbles for characters with dementia (Figure 1). The messages conveyed via this exercise included: 'See me, not my dementia'; 'I have dementia, but I'm still able to live well' and 'It takes a little longer, but we get there'. Participants therefore appeared to favour what have been described as 'quest' narratives (Frank 1995: 115), in which patients '... accept illness and seek to use it [original emphasis]' as they emphasised the positive aspects of dementia and talked about the opportunities that it had given them. They stressed that, while the story needed to be realistic, it should also show that it is possible to live well with dementia.

\section{Figure 1: Example of speech bubble completion activity}

One of the early drafts we shared with the group showed a character having difficulty remembering her PIN to withdraw money at the bank. This was an example of the type of everyday problem the group had shared with us, but they did not like the fact that, in the draft comic strip, this problem was left unresolved. They wanted the comic to acknowledge issues faced by people with dementia, but felt it was important to show possible solutions to problems, rather than leaving characters feeling confused or hopeless as we inadvertently had done. In subsequent drafts, we therefore drew on experiences the group had shared with us to identify potential solutions that demonstrate how difficulties might be overcome or mitigated.

\section{Developing characters}

As well as identifying key messages, participants also developed character profiles for the main characters in the comic. These included details of their dementia and how it affects them, but placed greater emphasis on details such as their family and hobbies. In line with Kitwood's (1997: 8) notion of preserving the 'personhood' of individuals with dementia, and thus implying 'recognition, respect and trust', the characters, named by the group as Jack and Mary, developed noticeably different personalities as the creative process progressed. For example, Mary is seen as more sociable, whilst Jack has a tendency to be more melancholy. 
Another important message emphasised by the group was the importance of a support network. Although we wanted the comic to focus on the person with dementia rather than their family, this could potentially lead to the characters appearing quite isolated. Participants in the peer support group stressed the importance of showing the value of support - from peers, family, professionals and more widely in the community - to reinforce the message that living well with dementia is not something that can be achieved alone. We, therefore, created a series of characters who would interact with, and support, the people with dementia in the comic, including family members, but also people within the wider community, such as service sector staff.

The group also actively participated in deciding the characters' appearance, including hairstyles and clothing. This input proved to be an important part of the overall process. Early sketches of the characters included aspects that the group pointed out to be stereotypes of elderly people and not accurate to the ages and personalities of Jack and Mary. Based on this feedback, we were able to improve the character design and avoid perpetuating misconceptions about people with dementia.

\section{The format, design and layout of the comic}

The feedback we had gathered about reactions to existing comics during the preparatory stage was valuable in helping to make decisions about the design of the comic we would create. We were keen to ensure that the comic was accessible to people with dementia themselves, but also to readers of a range of ages and literacy skills (including visual literacy). We therefore opted for a simple four-panel layout that was easy to follow and remained consistent throughout the comic. Based on participants' preferences, we opted for full colour rather than either black and white, or a limited or muted colour palette. In addition, the style of the images was clear and simple, rather than more complex or abstract representations. (Figure 2)

Figure 2: Cathy Leamy, Jack Has Some Help. Courtesy of Cathy Leamy

The amount of text is limited to ensure reading the comic does not require long periods of concentration. However, we decided against a wordless comic, or one with very limited text, as this form of storytelling is often more complex than it first appears and requires the reader to make sophisticated connections between, or within, images. All the text is in the form of dialogue, making the story easy to read aloud and share, or to act out. In 
addition, the comic is divided into short one or two page mini-stories that can be read individually, to discuss particular issues or to make the comic accessible to readers who might struggle to read a longer story in a single reading. Each mini-story section has a title that reminds the reader of the characters' names - a deliberate choice that both supports readers with cognitive problems and allows the mini-stories to be more easily shared individually.

In addition to contributing to decisions about key messages, characters and design, the insights into living with dementia offered by participants informed aspects of the final story in more subtle ways. For example, Mary's colour-coded diary and Jack's love of gardening were developed from group discussions about ways they had found to cope better with dementia.

\section{Naming the comic}

The title of the co-created comic, 'There's No Bus Map for Dementia', was selected collaboratively by participants from a number of suggestions put forward by the project team. The idea that everyone progresses at different rates and there's no single 'map' for dementia first arose in one of the initial activities, when participants were asked to draw visual metaphors that represented dementia for them. This produced a variety of responses, but it was striking that a number of participants drew routes, maps or forms of transport. Furthermore, the theme of 'journeys' was suggested by group members in our early discussions. We talked about both practical issues facing people with dementia, for example, having to stop driving and problems using public transport, and also the metaphor of dementia as a journey. It is argued that metaphors can make the impact of dementia more tangible and allow people to make sense of their condition (Cope, 2014). However, the use of metaphors can be problematic, in particular, if they perpetuate or reinforce negative perceptions of a condition. There are many metaphors that are commonly used when discussing dementia, including as a battle or invasion; as a monster or a thief who steals a happy life; zombies; or broken machines (for examples, see Behuniak 2011; Cope 2014; Golden et al 2012; Van Gorp and Vercruysse 2012). However, Cope's (2014) study of health communication texts found that the most common metaphor was 'dementia is a journey'.

The idea of 'dementia as a journey', or more broadly, that of a 'patient journey', is of course a common metaphor - or even a cliché. However, transforming such idiomatic metaphors into verbo-pictorial metaphors that combine text and image in a comic can 'awaken' the metaphor and make it more salient for the audience (Muller 2008: 208). In 
addition, the comic created in this project disrupts the typical idea of a 'patient journey' that sets out a coherent, chronological series of events (e.g. Health for America 2016; Northern Devon Healthcare 2017). Instead, it emphasises that, whilst dementia might be thought of as a journey, it is an individual one for which there is no map to follow. The comic also challenges the more familiar framing of dementia as a 'downhill' journey (e.g. Golden at al, 2012) by emphasising that, with support, the journey need not be a negative one.

\section{Conclusion}

The process described in this article has helped to develop greater understanding of how people with dementia choose to represent themselves and their condition in a comics art form. Of course, the comic produced represents the views shared by a small group and had we worked with another group of people with dementia, the outputs would almost certainly have been different. However, the method of comics creation piloted in this project could be adopted with other groups living with dementia, as well as other potentially vulnerable patient groups, thus facilitating greater involvement in the arts among such groups as well as greater understanding of complex conditions.

Involvement in the creative process has also had positive outcomes for participants themselves. As one of the dementia advocates involved commented,

Members are delighted with the outcome noting how all their comments, ideas and thoughts are in the comic. The activity has certainly helped to support members in their mission to show you can live well with dementia and be a productive member of society. Producing the comic has given members who are already proactive a desire to be involved with more initiatives relating to dementia.

Their positive response to the project was demonstrated by the fact that all members of the group chose to take part in a 'launch event' for the comic - exceeding our expectations. Through this event and many other dissemination activities undertaken by the peer support group and dementia advocates, as well as the research and artists, the comic has been distributed widely (free of charge) in both print and online formats ${ }^{2}$, including to other dementia support organisations; to health and social care workers; directly to people with dementia and their carers; to more general health or disability support organisations; amongst researchers and artists working in this field; and to libraries and other community organisations. 
As Van Gorp and Vercruysse (2012: 1279) point out in their analysis of dementia across a range of media, 'what is missing is the voice of those with dementia themselves'. Cohen-Shalev and Marcus (2012: 73) agree that, in the case of film, while the number of portrayals of dementia may have increased, 'only a few access the subjective world and acknowledge the personhood of people with dementia. However, as Capstick et al (2015) demonstrate, again in the case of film, people with dementia are able to participate for themselves in the production of resources for educational and consciousness-raising purposes through a process of co-production. Similarly, in the creation of graphic narratives about the experience of dementia, this project has shown that people with dementia and artists are able to work collaboratively to co-produce graphic narratives that portray people with dementia in ways that they wish themselves to be seen, rather than how others might perceive them. As Zeilig (2014: 172) writes, 'If we can begin to imagine dementia we can also start to confront some of the assumptions that we have about the disease and its sufferers'. Overcoming the stigma surrounding dementia is not an easy task, but perhaps graphic narratives co-authored by people with dementia themselves, such as the one created in this project, can play a role in reducing the fear dementia can provoke and in communicating the message that people with dementia do not lose their identity and, above all, not their humanity.

\section{Acknowledgements}

Many thanks to Betty Machin and Jane Snape from the Beth Johnson Foundation, Stoke-onTrent, and to members of the Peer Advocacy Support Group: Rita, Sue, Maq, John, Michael, Gordon, Fred, Shelagh and Dave. Thanks to Jessica Lucas who supported the group with arts activities. This project was funded by Arts Council England.

\section{References}

Alzheimer's Disease International (ADI) (2015), Dementia Statistics, https://www.alz.co.uk/research/statistics. Accessed 9 Dec 2019.

Alzheimer's Society (2019). Facts for the media, https://www.alzheimers.org.uk/aboutus/news-and-media/facts-media Accessed 12 Dec 2019.

Alzheimer's Society (2016), Over Half of People Fear Dementia Diagnosis, https://www.alzheimers.org.uk/news/2018-05-29/over-half-people-fear-dementiadiagnosis-62-cent-think-it-means-life-over. Accessed 12 Dec 2019.

Alzheimer's Society (2014), Dementia 2014: Opportunity for Change, London: Alzheimer's Society. 
Aquilina, Carmelo and Hughes, Julian C. (2006), 'The return of the living dead: Agency lost and found?', in C. Hughes, S.J. Louw and S.R. Sabat (eds), Dementia: Mind, Meaning, and the Person, Oxford: Oxford University Press, pp. 143-161.

Ashwell, Gary and Thomas, Alex (2018), 'Are comic books appropriate health education formats to offer adult patients?', AMA J Ethics, 20: 2, p.134-140.

Bamford, Sally-Marie, Holley-Moore, George and Watson, J.essica (2014), Compendium of Essays: New Perspectives and Approaches to Understanding Dementia and Stigma, London: ILC-UK.

Beard, Renee Lynn. (2004), 'In their voices: Identity preservation and experiences of Alzheimer's disease', Journal of Aging Studies 18: 4, pp. 415-28.

Behuniak, Susan M. (2011), 'The living dead? The construction of people with Alzheimer's disease as zombies', Ageing and Society 3: 1, pp.70-92.

Blay Sergio. L. and Peluso Erica T.P. (2010). 'Public stigma: The community's tolerance of Alzheimer disease', American Journal of Geriatric Psychiatry 18:2, pp. 163-71.

Bond, John, Corner, Lynne and Graham, Ruth (2004), 'Social science theory on dementia research: Normal ageing, cultural representation and social exclusion', in A. Innes, C. Archibald and C. Murphy (eds), Dementia and Social Inclusion: Marginalised Groups and Marginalised Areas of Dementia Research, London: Jessica Kingsley.

Brodaty, Henry and Donkin. Marika (2009), 'Family caregivers of people with dementia', Dialogues in Clinical Neuroscience 11:2, pp. 217-28.

Capstick, Andrea, Chatwin, John, and Ludwin, Katherine (2015), 'Challenging representations of dementia in contemporary Western fiction film: From epistemic injustice to social participation', in A. Swinnen and M. Schweda (eds), Popularizing Dementia: Public Expressions and Representations of Forgetfulness, Bielefeld, Germany: transcript, pp. 229-51.

Clarke, Juanne N. (2006), 'The case of the missing person: Alzheimer's disease in mass print magazines 1991-2001', Health Communication 19: 3, pp. 269-76.

Cohen-Shalev, Amir and Marcus, Esther-Lee (2012), 'An insider's view of Alzheimer: Cinematic portrayals of the struggle for personhood', International Journal of Ageing and Later Life, 7: 2, pp. 73-96.

Cope, Emily (2014), 'Fighting dementia: A study exploring the metaphorical representation of dementia in health communication', PhD. dissertation, Cardiff: University of Cardiff. 
Danziger-Russell, Jacqueline (2013), Girls and Their Comics: Finding a Female Voice in Comic Book Narrative, Lanham: Scarecrow Press.

Demetris, Alex (2015), Dad's Not All There Anymore, London: Jessica Kingsley Publishers.

Fetherstonhaugh, Deirdre, Tarzia, Laura and Nay, Rhona (2013), 'Being central to decision making means I am still here! The essence of decision making for people with dementia', Journal of Aging Studies 27: 2, pp. 143-150.

Faridi, Zubaida, Grunbaum, Jo Anne, Gray, Barbara Sajor, Franks, Adele and Simoes, Eduardo (2007), 'Community-based participatory research: necessary next steps', Preventing Chronic Disease, 4: 3, http://www.cdc.gov/pcd/issues/2007/jul/06_0182.htm. Accessed 12 Dec 2019.

Frank, Arthur W. (1995), The Wounded Storyteller: Body, Illness, and Ethics, Chicago: University of Chicago Press.

Goffman, Erving (1963), Stigma. Notes on the Management of Spoiled Identity, Englewood Cliffs, NJ: Prentice Hall.

Golden, Mindi Ann, Whaley, Bryan B., and Stone, Anne M. (2012), “"The system is beginning to shut down": Utilizing caregivers' metaphors for dementia, persons with dementia, and caregiving', Applied Nursing Research 25: , pp. 146-151.

Green, Michael J. and Myers, Kimberley R. (2010), 'Graphic medicine: Use of comics in medical education and patient care', BMJ 340: , pp. c863.

Health for America (2016), A Stroke Patient's Journey, https://www.blog.healthforamerica.org/single-post/2016/11/11/Picturing-a-PatientsStroke-Journey. Accessed 12 Dec 2019.

Hellström, Ingrid, Nolan, Mike. Nordenfelt, Lennart and Lundh, Ulla (2007), 'Ethical and methodological issues in interviewing people with dementia', Nursing Ethics 14: 5, pp. 608-19.

Hillman, Alexandra and Latimer, Joanna (2017), 'Cultural representations of dementia', PLoS Med 14: 3, pp. e1002274.

Husband, Tony (2014), Take Care, Son: The Story of My Dad and his Dementia, London: Constable and Robinson Ltd.

Kirkman, Allison M. (2006), 'Dementia in the news: The media coverage of Alzheimer's disease', Australian Journal on Ageing, 25: 2, pp. 74-9.

Kitwood, Tom (1997) Dementia Reconsidered: The Person Comes First, Maidenhead: Open University Press. 
Leavitt, Sarah (2010), Tangles: A Story about Alzheimer's, My Mother, and Me, New York: Skyhorse Publishing.

Leibing, Annette (2015), 'Dementia in the making: Early detection and the body/brain in Alzheimer's disease', in A. Swinnen and M. Schweda (eds), Popularizing Dementia: Public Expressions and Representations of Forgetfulness, Bielefeld, Germany: transcript, pp. 275-94.

McKeown, Jane, Clarke, Amanda, Ingleton, Christine and Repper, Julie (2010), 'Actively involving people with dementia in qualitative research', Journal of Clinical Nursing 19:13/14, pp. 1935-43.

McNicol, Sarah (2019) 'Creating a comic about living with dementia', Age of Creativity, http://www.ageofcreativity.co.uk/assets/pdfs/There's\%20No\%20Bus\%20Map\%20for \%20Dementia.pdf. Accessed 4 May 2020.

McNicol, Sarah (2017), 'The potential of educational comics as a health information medium', Health Information and Libraries Journal, 34:1, pp. 20-31.

Muller, Cornelia (2008), Metaphors Dead and Alive, Sleeping and Waking, Chicago: University of Chicago Press.

Naue, Ursula and Kroll, Thilo (2009), “"The demented other”: identity and difference in dementia', Nursing Philosophy 10, pp. 26-33.

Northern Devon Healthcare (2017), A Typical Patient Journey, https://www.northdevonhealth.nhs.uk/services/stroke-services/a-typical-patientjourney/. Accessed 12 Dec 2019.

Sweeting, Helen and Gilhooly, Mary (1997), 'Dementia and the phenomenon of social death', Sociology of Health and Illness, 19, pp. 93-117.

Swinnen, Aagje and Schweda, Mark (eds.) (2015), Popularizing Dementia: Public Expressions and Representations of Forgetfulness, Bielefeld, Germany: transcript.

Tanner, Denise (2013), 'Co-research with older people with dementia: Experience and reflections', Journal of Mental Health, 21:3, pp. 296-306.

Van Gorp, Baldwin and Vercruysse, Tom (2012), 'Frames and counter-frames giving meaning to dementia. A framing analysis of media content', Social Science and Medicine 74:8, pp. 1274-81.

Werner, Perla (2005), 'Social distance towards a person with Alzheimer's disease', International Journal of Geriatric Psychiatry 20, pp. 182-8. 
Werner, Perla, Goldstein, Dovrat and Buchbinder, Eli (2010), 'Subjective experience of family stigma as reported by children of Alzheimer's disease patients', Qualitative Health Research 20:2, pp. 159-69.

Zeilig, Hannah (2014), 'Gaps and spaces: Representations of dementia in contemporary British poetry', Dementia 13:2, pp. 160-75.

\section{Contributor details}

Sarah McNicol is a Research Associate at the Education and Social Research Institute at Manchester Metropolitan University. Her research interests are focused around the uses of comics to share health and other information, and innovative ways of working with participants in community settings.

Contact: Education and Social Research Institute at Manchester Metropolitan University, All Saints Building, All Saints, Manchester, M15 6BH, UK

E-mail: s.mcnicol@mmu.ac.uk

Orcid: 0000-0001-8196-6680

Cathy Leamy is a Boston-based cartoonist and a health communication specialist. She has a master's in health communication from Tufts University School of Medicine, as well as qualifications in computer science and a graphic design. She has worked in multiple clinical support positions, including medical editor and writer, and front desk work.

E-mail: Catherine.leamy@gmail.com

\footnotetext{
${ }^{1}$ see http://www.graphicmedicine.org/ and https://sites.google.com/site/healtheducationcomics/ for numerous examples

${ }^{2}$ Details available at https://www.mmu.ac.uk/esri/research/projects/dementia-comics/
} 